\title{
Removal Bismarck Brown G dye from Aqueous Solution Over a Composite of Triazole-Polyvinyl Chloride Polymer and Zinc Oxide
}

\author{
NOUR ABD ALRAZZAK ${ }^{1 *}$,SAADON ABDULLA AOWDA² and ABBAS JASSIM ATIYAH ${ }^{2 *}$ \\ 'University of Babylon, College of Science of Women's, Department of Chemistry, \\ Hilla, Post Box 4, Iraq. \\ ${ }^{2}$ University of Babylon, College of Science, Department of Chemistry, \\ Hilla, Post Box 4, Iraq. \\ ${ }^{*}$ Corresponding author E-mail: abbaslafta2009@yahoo.com
}

http://dx.doi.org/10.13005/ojc/330541

(Received: July 10, 2017; Accepted: August 14, 2017)

\section{ABSTRACT}

The present study involves synthesis a composite of triazole-poly vinyl chloride (PVC) polymer with nano-crystalline zinc oxide to yield triazole-PVC/ZnO. The produced composite was characterized using fouier infrared spectroscopy (FTIR), X-Rays diffraction (XRD) and micro- elemental analysis $(\mathrm{CHN})$. The activity of the produced composite with respect to neat zinc oxide was investigated by following both of adsorption and photocatalytic removal of Bismarck Brown G (BBG)dye from their aqueous solutions. The obtained results in this study showed that triazole-PVC/ZnO was more efficient than neat $\mathrm{ZnO}$ on dye removal for both of adsorption and photocatalytic reaction.

Keywords: Zinc oxide, Composite materials, Thiazine polymer, Adsorption processes, Dye removal from aqueous solutions.

\section{INTRODUCTION}

In last few years nano materials have much attention and are become a topic research over our world due to their massive importance in our modern life. Among wide variety of these Nano scale materials ${ }^{1-3}$, Nano crystalline zinc oxide is very important photocatalytic material that is used currently in wide range of applications in different fields ${ }^{4}$. These involve gas sensors, solar cells, semiconducting photocatalyst, industrial catalyst, and electrical and optical devices. Beside these applications, zinc oxide was more attractive photocatalytic material due to its excellent physical and chemical properties, such as thermal and chemical stability, no toxicity, relatively low cost as 
well as it is capable of recovery with high efficiency to be recycled after each use after very simple reactivation processes ${ }^{5,7}$. Zinc oxide can be excited thermally and/or photoexcited via absorption of light with energy that is equal to or greater its bandgap ( $h v \geq E g$ ) which is equal to $2.31 \mathrm{eV}^{8-10}$. Upon excitation, its produced $\left(\mathrm{h}^{+}, \mathrm{e}-\right)$ pairs on both valence band and conduction band respectively. These species then are migrated to the surface to participate on redox reactions with pre-adsorbed species on the surface. The main drawback in this point is the recombination reaction that occurs normally between conduction band electrons and valence band holes ${ }^{11-13}$. This process would affect negatively on the activity of zinc oxide as a photocatalyst. So that the goal point here is how to prevent or at least reduce the rate of recombination reaction. Different methods can be applied to perform the photocatlytic activity of zinc oxide and increase the time of charge separation of $\left(h^{+}, e-\right)$ pairs ${ }^{14,15}$. These involves surface modification by coupling with another photocatalyst with smaller bandgap, doping of some reactive metal with $\mathrm{ZnO}$, surface sensitization, doping with some of non-metals ${ }^{16}$. In addition to these method, zinc oxide surface can be modified by combination with polymeric materials by absorption or reaction with dispersed polymer on its surface ${ }^{17}$.

The present study describe modification of the activity of zinc oxide by combination with polytriazole to yield triazole-PVC/ZnO and the activity of the formed composite would be investigated by following removal of BBG dye over surface of neat zinc oxide and triazole-PVC/ ZnO.

\section{EXPERIMENTAL}

\section{Chemicals}

Poly vinyl chloride $99.9 \%$ Sigma Aldrich Company, Pyridine $99.8 \%$ sigma Aldrich company, tetra hydro furan $99.5 \%$ sigma Aldrich company.

\section{Using zinc oxide}

Used zinc oxide was $\mathrm{ZnO}$ nanoparticle (ZnO,Fluka company, 99.5\%) with average nanoparticle of 25-30 nm. The dye used was Bismarck brown G (BBG- Sigma Aldrich). It has a molecular formula $(\mathrm{C} 21 \mathrm{H} 24 \mathrm{~N} 8.2 \mathrm{HCl})$. This dye has a maximum absorption at a wavelength of $468 \mathrm{~nm}$ and it was obtained from AlHilla Textile Factory.

\section{Synthesis of triazole-PVC polymer}

4-Hydrazino-5-methoxy cinnolin $(0.0304$ $\mathrm{gm}, 0.0016 \mathrm{~mole}$ ) was added to $(0.125 \mathrm{~g})$ poly (vinyl chloride) and few drops of pyridine in $(50 \mathrm{ml})$ tetrahydrofuran (THF) .A brown prcipitate was formed after refluxing the mixture for 5 hours. The modified polymer (P1) was filtered, washed with redistilled water, methanol, ether and dried under vacuum. (0.00057 mole, $0.2 \mathrm{~g})$ of 1-((4-(5-mercapto$4 \mathrm{H}-1,2,4$-triazol-3-yl)phenyl)diazenyl)naphthalen2-ol [N1] was added to $(0.1 \mathrm{~g})$ of poly (vinyl chloride) and (3) drops of pyridine in (15) ml THF, which reflux for $5 \mathrm{~h}$, the solvent was evaporate and the orange solid product was obtain ${ }^{18}$. Schematic description for polymer synthesis is shown in Figure.1.

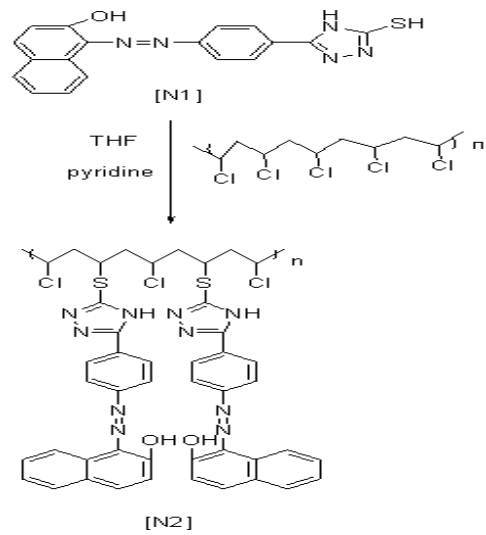

Fig. 1. Schematic description for the route for synthesis of modified triazole -PVC polymer

Synthesis of a composite of modified triazolePVC/ZnO

A composite of $\mathrm{P} / \mathrm{ZnO}$ was synthesized as follows : $1 \mathrm{gm}$. of zinc oxide nanoparticles was suspended in $100 \mathrm{ml}$ of distilled water with continuous stirring at $30^{\circ} \mathrm{C}$ for 60 minute. In another flask $0.02 \mathrm{gm}$ of triazole polymer was suspended in $100 \mathrm{ml}$ of distilled water with continuous stirring at $50^{\circ} \mathrm{C}$ for 2 hours. Then these two suspended solutions were mixed together in one flask with continuous stirring for $4 \mathrm{~h}$. at $35^{\circ} \mathrm{C}$ under normal atmospheric conditions. Then the obtained mixture was left aside for $2 \mathrm{~h}$, to cool to room temperature and the it filtered out. The precipitate washed with water for several times and the obtained solid was dried in oven at $110^{\circ} \mathrm{C}$ for over night. The obtained composite was investigated using FTIR spectroscopy, XRD patterns, and $\mathrm{CHN}$ microelemental analysis. 
Adsorption and photocatalytic activity of triazolePVC/ZnO

The activity of both neat zinc oxide and the composite $\mathrm{P} / \mathrm{ZnO}$ was investigated via removal of BBG dye from aqueous solution by adsorption and phtocatalytic reaction. To perform this part a series of experiment were carried out using solution of dye $50 \mathrm{ppm}$. This was suspended in a reaction cell in $30 \mathrm{ml}$ in a homemade phtoreactor as shown in Fig. 2. Adsorption processes were carried out in $30 \mathrm{ml}$ conical flask using a thermal controlled shaker water bath under air conditions. For each experiment, a sample containing a dye concentration of $50 \mathrm{ppm}$ in $30 \mathrm{ml}$ was suspended with a desired mass of a used catalyst (neat $\mathrm{ZnO}$ and triazole-PVC/ZnO). All adsorption processes were conducted for $1 \mathrm{~h}$. for each run, periodically $1 \mathrm{ml}$ of the reaction mixture was withdrawn for each $15 \mathrm{~min}$. for each experiment ${ }^{19}$. Samples then were centrifuged for several times and the absorbance of the supernatant obtained liquid was recorded at a wavelength of $468 \mathrm{~nm}$ using UV-Visible Spectrophotometer Shimadzu 1650 PC-UV-visible. The efficiency for dye removal from the simulated industrial wastewaters $(\mathrm{R} \%)$ was calculated using the following relationship ${ }^{19}$

Removal\% $=C_{i}-C_{t} / C_{i} \times 100$

Where $C_{i}$ is the initial dye concentration and $\mathrm{C}_{t}$ is the dye concentration that is remaining at interval time of adsorption process.

Photocatalytic activity of $\mathrm{ZnO}$ and triazole$\mathrm{PVC} / \mathrm{ZnO}$ was investigated by following phtocatlytic removal of BBG dye over these catalysts. To perform

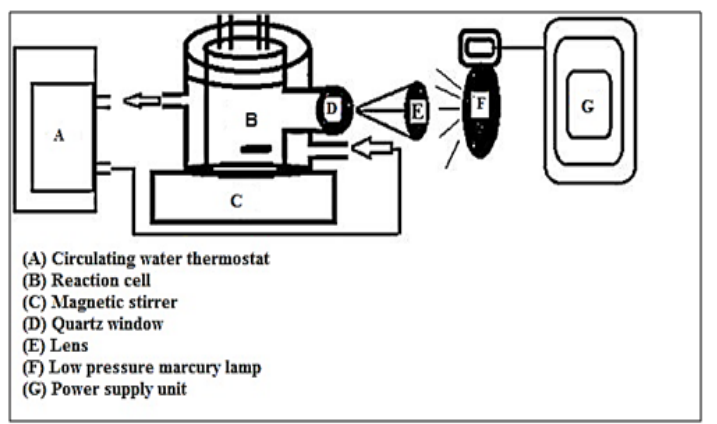

Fig. 2. Apparatus for adsorption and photocatalytic reactions for BBG dye removal over both neat $\mathrm{ZnO}$ and triazole-PVC/ZnO that, a series of experiments were carried out under different reaction conditions. These experiments were performed using a solution of BBG dye with a suspension of $\mathrm{ZnO}$ and triazole-PVC/ZnO. All reactions were carried out in the homemade photoreactor that is shown in Fig. 2 above. For each experiment, same amount of dye was used $(30 \mathrm{ml}, 50 \mathrm{ppm})$ over a suspension of the used $\mathrm{ZnO}$ or triazole-PVC/ZnO) catalysts $(0.10 \mathrm{gm})$. Reaction mixture was mixed using magnetic stirrer for $20 \mathrm{~min}$. in the dark for each run in order to approach adsorption equilibrium. Then irradiation was flushed with UV radiation using low pressure mercury lamp (150) watt (type TQ150 Z2 supplied by Karl Kolb company). Then periodically, at each $15 \mathrm{~min}$. by withdrawing of $1 \mathrm{ml}$ of the reaction mixture. This withdrawal sample was centrifuged carefully at $5000 \mathrm{rpm}$. The photocatalytic BBG dye removal over each of $\mathrm{ZnO}$ and triazole-PVC/ZnO was calculated by recording the absorbance of the supernatant liquid at a wavelength of $468 \mathrm{~nm}$ with Shimadzu 1180 UV-Vis Spectrophotometer.

\section{Fourier transform infrared spectroscopy (FTIR)}

Surface functional groups of both of $\mathrm{ZnO}$ and triazole-PVC/ZnO were conducted using FTIR spectroscopy. In all runs, FTIR spectra were investigated using FTIR Perkin Elminer Spectrophotometer. All spectra were recorded from 400 to $4000 \mathrm{~cm}^{-1}$. Samples were dried carefully and then mixed with $\mathrm{KBr}$ powder to make them as pellets prior to perform run.

\section{X-rays diffraction (XRD)}

Crystal structure of both $\mathrm{ZnO}$ and triazole-PVC/ZnO was investigated with XRD, Simadzu-6000 X-rays diffractmeter. The used XRD diffractmeter was provided with a nickel filter, and the radiation source was CuK $\alpha$ radiation at $40 \mathrm{kV}$ and $30 \mathrm{~mA}$. All XRD patterns were recorded in the range of 2 Theta $=20-80$ deg.

\section{Microelemental analysis (CHN)}

Microelemental analysis for each of $\mathrm{ZnO}$ and triazole-PVC/ZnO samples was investigated to estimate the content of $\mathrm{C}, \mathrm{N}$ and $\mathrm{H}$ content for these materials using Euro EA3000 Elemental Analyzer, Italy. 


\section{RESULTS AND DISCUSSION}

Polymer and Catalyst characterization Fourier transform infrared spectroscopy for triazole-PVC and the composite

A modified PVC/triazole polymer was synthesized as described above. The formed polymer was investigated using FTIR specrum as shown in Fig. 3. Weak band around $635 \mathrm{~cm}-1$ can be assigned to $(\mathrm{C}-\mathrm{Cl})$ vibration modes. The band around $1554 \mathrm{~cm}^{-1}$ indicated that the end groups of the Polymer is $\mathrm{C}=\mathrm{C}$. The band around $2920 \mathrm{~cm}^{-1}$ can be assigned to aliphatic $(\mathrm{C}-\mathrm{H})$. The band around $3070 \mathrm{~cm}^{-1}$ is related to $\mathrm{C}-\mathrm{H}$ aromatic and that around $2936 \mathrm{~cm}^{-1} \mathrm{C}-\mathrm{H}$ aliphatic ${ }^{20}$. The band around $1569 \mathrm{~cm}^{-1}$ is assigned to $\mathrm{C}=\mathrm{C}$, and that around $1648 \mathrm{~cm}^{-1}$ is related to $\mathrm{C}=\mathrm{N}$. The band around $3379 \mathrm{~cm}^{-1}$ is assigned to $\mathrm{N}-\mathrm{H}$ Stretching mode, and that around $1457^{-1}$ is related to $\mathrm{C}-\mathrm{H}$ bending of $-\mathrm{CH} 2$. The band around $737^{-1} \mathrm{C}-\mathrm{H}$ bending of ortho substituted benzene ring. The band around $3448 \mathrm{~cm}^{-1}$ is assigned to $\mathrm{OH}$ stretching modes $^{20}$. The band around $3321 \mathrm{~cm}^{-1}$ is attributed to $\mathrm{NH}$ stretching modes. The band around 3078 $\mathrm{cm}^{-1}$ can be assigned to the aromatic $\mathrm{CH}$ stretching modes. The band around $1554 \mathrm{~cm}^{-1}$ is assigned to $\mathrm{C}=\mathrm{N}$ stretching modes. The band around $1485 \mathrm{~cm}^{-1}$ is attributed to $\mathrm{C}=\mathrm{C}$ aromatic stretching modes. The band around $1342 \mathrm{~cm}^{-1}$ is related to $\mathrm{C}-\mathrm{N}$ stretching modes $^{21}$.

FTIR spectra for triazole-PVC/ZnO composites are shown in Fig. 4. From these spectra it can be seen that, signals of triazole-PVC are almost appeared in FTIR spectra of the composites. From these spectra, the bands that appear $500-650 \mathrm{~cm}^{-1}$ are assigned to metal oxide ( $\left.\mathrm{Zn}-\mathrm{O}\right)$ bonds ${ }^{22,23}$. The bands at the range of $950-1480 \mathrm{~cm}^{-1}$ are attributed to the presence of stretching and bending

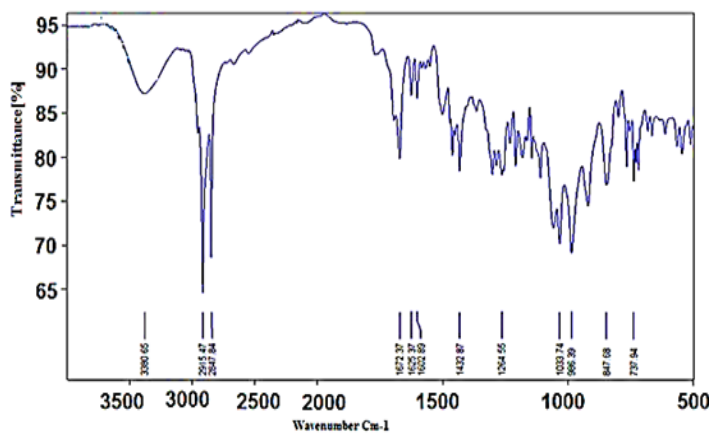

Fig. 3. FTIR spectra for triazole-PVC of oxygen at the surface triazole-PVC/ZnO composite. bands around $1640 \mathrm{~cm}-1$ and that around $3445 \mathrm{~cm}^{-1}$ are assigned to the stretching modes of $\mathrm{OH}$ groups on the surface of triazole-PVC/ $\mathrm{ZnO}$ composite. The band around $3400 \mathrm{~cm}^{-1}$ is assigned to vibration mode of $\mathrm{O}-\mathrm{H}$ group the composite surface ${ }^{24,25}$.

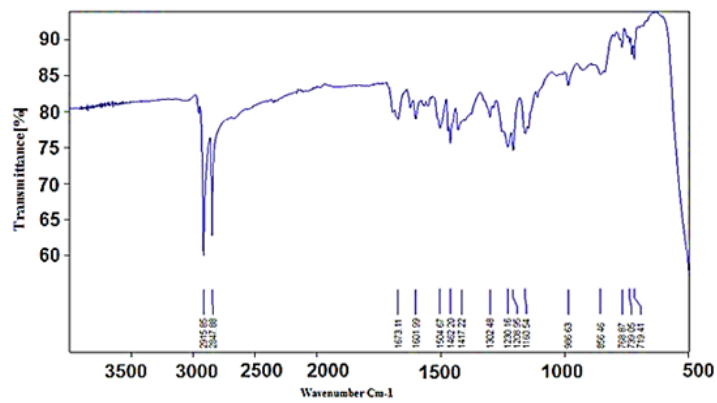

Fig. 4. FTIR for triazole-PVC/ZnO

\section{X-Rays Diffraction(XRD)}

XRD patterns for both $\mathrm{ZnO}$ and triazole-PVC/composites are shown in Figs. 5 and 6 . From these XRD patterns for neat and modified $\mathrm{ZnO}$ with triazole - PVC, it can be seen that, the main peaks for $\mathrm{ZnO}$ are appeared in two cases and it is showed wurtzite type hexagonal structure; (Joint card of powder diffraction standards, JCPDS 36-1451 card) for $\mathrm{ZnO}$ samples $^{26,27}$. The peaks at $21 \theta$ of $31.7^{\circ}$, $34.5^{\circ}, 36.2^{\circ}, 47.5^{\circ}, 56.5^{\circ}, 67.94,69.08,72.5$ and 76.95 are corresponded to the crystal planes (100), (002), (101), (102), (110), (112), (201),(004)and( 202) of crystalline $\mathrm{ZnO}$. This means that doping zinc oxide with triazole-PVC in this ratio doesn't affect its crystallite structure. For this reason XRD patterns of triazole-PVC/ $\mathrm{ZnO}$ almost showed same patterns for neat zinc

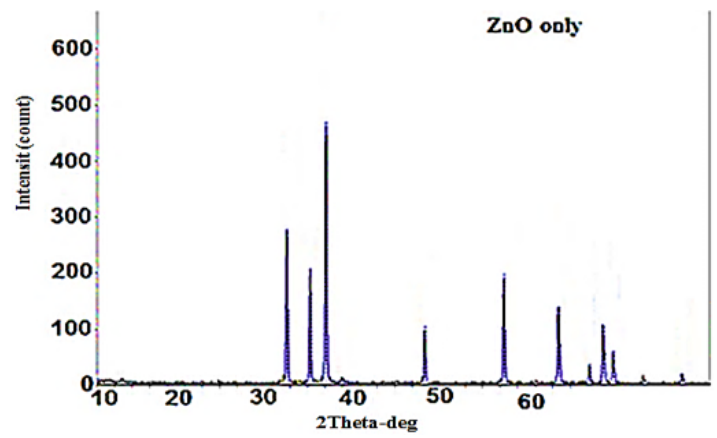

Fig. 5. XRD patterns for neat ZnO nanoparticles 


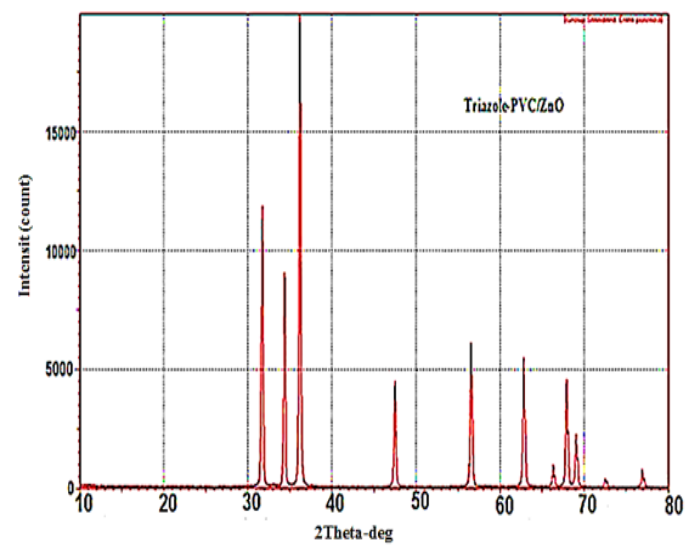

Fig. 6. XRD patterns for triazole-PVC/ZnO composites

oxide 26,27 .

\section{Microelemental analysis(CHN)}

Micoelemental content of neat $\mathrm{ZnO}$ and triazole-PVC/ZnO samples was investigated using $\mathrm{CHN}$ microelemental analysis and the obtained results are shown in Table 1. From these results it can be seen that there is a clear evidence for the formation of the proposed composite by presence these elements that composed the polymer on the matrix of zinc oxide.

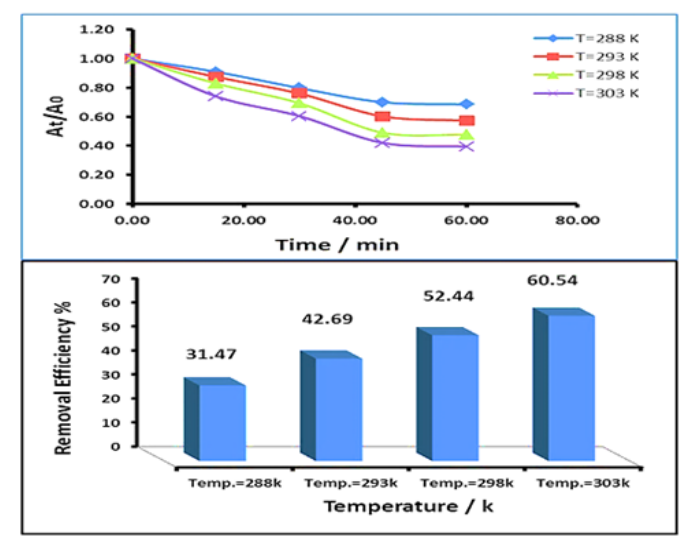

Fig. 7. Removal of BBG dye over neat $\mathrm{ZnO}$ by adsorption as a function of time at different temperatures

Table.1: Microelemental results for both neat $\mathrm{ZnO}$ and triazole-PVC/ZnO

\begin{tabular}{lccc}
\hline Sample & $\mathbf{C} \%$ & $\mathbf{H} \%$ & $\mathbf{N} \%$ \\
\hline ZnO neat nil & nil & 0.1 & nil \\
Triazole-PVC/ZnO & 1.8 & 0.2 & 0.6 \\
\hline
\end{tabular}

\section{Adsorption ability of BBG dye over $\mathrm{ZnO}$ and triazole-PVC/ZnO}

Adsorption ability of both neat zinc oxide and the prepared composite was investigated by investigating removal of BBG dye over $\mathrm{ZnO}$ and triazole-PVC/ZnO. The obtained results are presented in Figs. 7 and 8. From these results it can be seen that, the activity of triazole-PVC/ZnO was more efficient than neat $\mathrm{ZnO}$ in BBG dye removal from aqueous solution by adsorption process. This result can be attributed to enhancement surface properties of $\mathrm{ZnO}$ by doping with triazole-PVC. This can lead to increase porosity of the surface and this leads to increase its adsorption capacity for the composite in comparison with neat $\mathrm{ZnO}$. The effect of temperature on adsorption efficiency of $B B G$ dye over both neat $\mathrm{ZnO}$ and the composite, a series of experiments were carried out using same reaction conditions at a range of temperatures from 288 to $303 \mathrm{~K}$. The obtained results are shown in Figs. 7 and $8^{28}$. From these results it can be seen that the efficiency of dye removal was increased with increase in the temperature of reaction mixture for using both of neat $\mathrm{ZnO}$ and the composite and the maximum removal efficiency was obtained at $303 \mathrm{~K}$. These results can be attributed to the effect of temperature on the diffusion of BBG dye molecules from bulk solution into the adsorption sites on the surface of both $\mathrm{ZnO}$ and the composite ${ }^{21}$. Elevation in temperature of reaction mixture can lead to increase the rate of diffusion of dye molecules and this leads to increase the

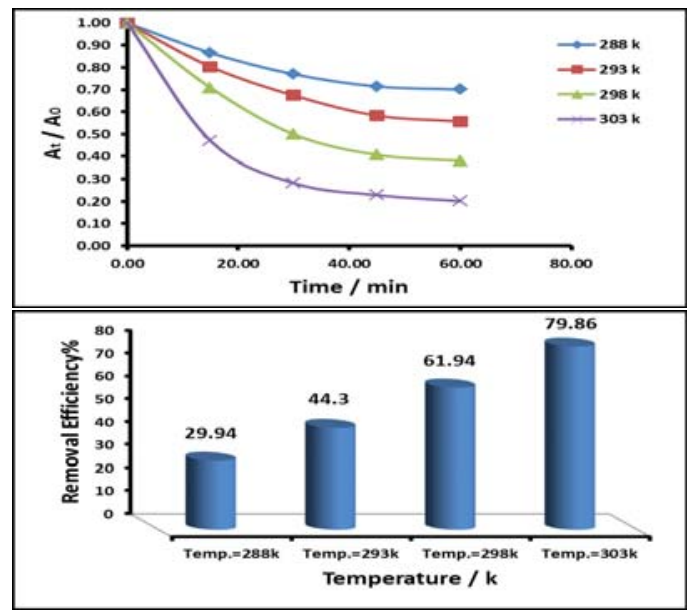

Fig. 8. Removal of BBG dye over triazole-PVC/ ZnO by adsorption as a function of time at different temperatures 
efficiency of dye removal upon increasing adsorption temperature in this range $\mathrm{e}^{29,30}$.

\section{Photocatalytic removal of BBG dye over $\mathrm{ZnO}$ and triazole-PVC/ZnO}

The photocatalytic activity of neat $\mathrm{ZnO}$ and triazole-PVC/ZnO was investigated by following removal of $B B G$ dye over a suspension of these materials. To perform that, a series of experiments were carried out and for each experiment $0.05 \mathrm{~g}$. of the used materials were suspended in $30 \mathrm{ml}$ of 50 ppm of BBG dye with continuous stirring under normal air conditions at range of temperatures from 288 to 303 with constant interval increment of 5 degree for each successive runs. Before starting light reaction, dark reaction was undertaken by stirring reaction mixture for around $15 \mathrm{~min}$. in dark to reach adsorption equilibrium. After that, photocatalytic reaction was initiated by irradiation with UV light from low pressure mercury lamp. The reaction temperature was controlled at a desired value using a thermostatic circulation water jacket. The obtained results of photocatalytic removal of BBG dye over a neat $\mathrm{ZnO}$ are shown in Fig. 9 and that for triazole-PVC/ZnO are shown in Fig.10 respectively.

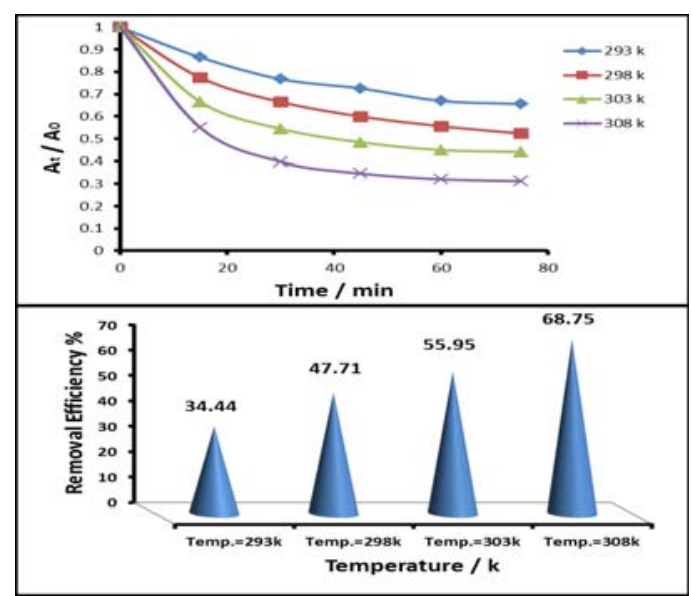

Fig.9. Removal of BBG dye over neat $\mathrm{ZnO}$ by potocatalytic reaction as a function of time at different temperatures

electron transfer from valence band into the conduction band through structure of particles of the catalyst. It is believed that enhancement in the efficiency of dye removal with increasing of reaction temperature is probably attributed to the effect of
From these results, it can be seen that using triazole-PVC/ZnO as a catalyst for dye removal was more efficient in comparison with use neat $\mathrm{ZnO}$ under applying the same reaction conditions. Better removal efficiency of BBG dye after one hour over composite was around $82 \%$ while it was around $68 \%$ over neat $\mathrm{ZnO}^{31,32}$. This significant enhancement in dye removal over composite can be attributed to the synergistic effect of triazole-PVC and $\mathrm{ZnO}$. Besides that, presence of triazole-PVC particles in this composite can reduce recombination reaction between conduction band electrons $\left(\mathrm{e}_{\mathrm{CB}}^{-}\right)$and valence band holes $\left(\mathrm{h}^{+}{ }_{\mathrm{VB}}\right)$ by increasing separation between these species $^{33}$.For neat $\mathrm{ZnO}$, recombination reaction occurs with high rate which leads to reduce the efficiency of the photocatalytic process. For composite, these species can migrate to the surface and then participate in redox reactions with the pre-adsorbed species on the surface of the coposite ${ }^{34}$. Also from the obtained results for both of neat $\mathrm{ZnO}$ and the composite it can be seen that the efficiency of BBG dye removal was increased with increase of temperature. It is well known that phtocatalytic reactions are not too sensitive towards elevation in reaction temperature and it depend mainly on

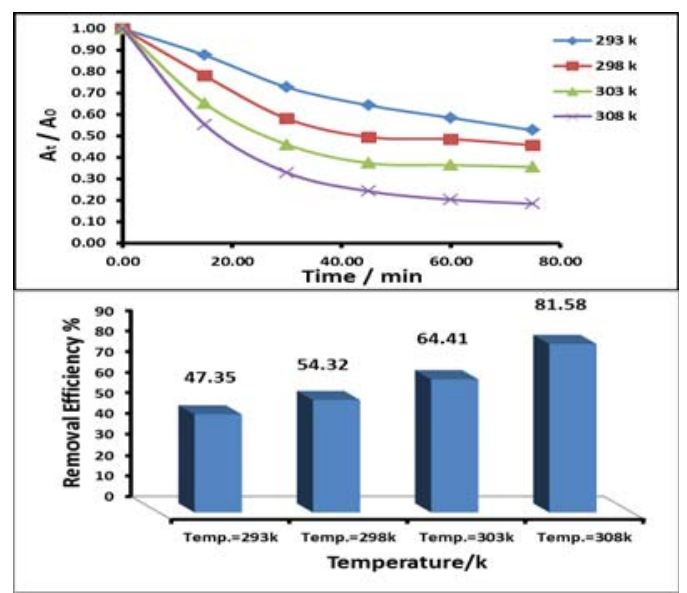

Fig.10. Removal of BBG dye over triazole-PVC/ ZnO composite by potocatalytic reaction as a function of time at different temperatures

temperature on the diffusion of dye molecules from bulk solution to the surface and its effect on adsorption-desorption processes for reacting species $^{35,36}$. 


\section{CONCLUSIONS}

From the obtained results in this study it was found that doping zinc oxide with triazole-PVC improved its surface properties. The composite
triazole-PVC/ZnO showed higher adsorption ability and photocatalytic activity in BBG dye removal from aqueous solution in comparison with using neat zinc oxide.

\section{REFERENCES}

1. Wang Z, Huang C, Huang Y, Hou Y, Xie P, Zhang B, Cheng H, Chem. Mater., 2001, 13, 678-682.

2. Xu J, Pan Q, Shun Y, Tian Z, Sens. Actuators, B. Chem., 2000, $66,277-279$.

3. Wu J, Xie C, Bai Z, Zhu B, Huang K, Wu R, Mater. Sci. Eng. B, Solid- State Mater. Adv. Technol., 2002, $95,157-161$.

4. Curridal M, Comparelli R, Cozzli P, Mascolo D, Mater. Sci. Eng., C, Biomin. Mater., Sens. Sys., 2003, $23,285-289$.

5. Shanthi M, Kuzhalosai V, India Journal of Chemistry, 2012, 51,428-434.

6. Garg K, Amita M, Kumar R, Gupta R, Dyes and Pigments, 2004 ,63(3), 243-250.

7. Amjed MO, Ahmed SF, Abbas JL, International Journal of Science and Research, 2014, 3(11), 2133-2138.

8. Dezhongyu J, Ruzuicai M, Zhihongliu R, Spectrochimica Acta Part A: Molecular and Biomolecular Spectroscopy, 2004, 60(7), 1617-1624

9. Attia A, Kadhim S, Hussein F, E- Journal of Chemistry, 2008, 5(2), 219-223.

10. Vinu R, Mudras G, Journal of the Indian Institute of Science, 2010, 90(2), 189-230.

11. Katarzyna S, Filip C, Magdalena N, Teofil J, Journal of Nanomaterial, 2012, 2012,1-19.

12. Huang M, Mao S, Feick H, Science, 2001, 292, 1897-1909.

13. Vayssieres L, Advanced Materials, 2003, 15,464-466.

14. Nitish R, Kam T, Debabrata P, The Journal of Physical Chemistry C, 2015,119 (33), 19117-19125.

15. Nitish R, Yohan P, Youngku S, Kam T, Debabrata P, Applied Materials Interfaces, 2014,6 (19), 16498-16507
16. Nakajima N, Kato H, Okazaki T, Sakisaka $Y$, Surface Science, 2004 , 561(1), 93-100.

17. Hong R, Qian J, Cao J, Powder Technology, 2006 , 163, 160-168.

18. Ulbrich K, llavský M, Dušek K, Kope'ek J, European Polymer Journal,1977, 13(7), 579-585.

19. Ameri A, Esrafily A, Iranian Journal of Environmental Health Sciences \& Engineering, 2013 , 10(19), 1-9.

20. Murti Y, Agnihotri R, Pathak D, American Journal of Chemistry, 2011,1(2), 42-46.

21. Olfa A, Radha B, National Journal of Chemistry, 2010, 3, 74- 85.

22. Jun S, Kim S, Han J,Journal Korean Ceramic Society, 1998, 35(3), 209-215.

23. Taps A, Majewaski P, Aldinger F, Journal of the American Ceramic Society, 2000,83 (12), 2954-2960.

24. Gouvea C, Wypych K, Moraes S, Duran N, Nagata N , Zamora P, Chemosphere, 2000, 40, 440-443.

25. Bourikas K, Stylidi M, Dimitris K, Verykios X, Langmuir, 2005, 21(12),9222-9230.

26. Ibhadon O, Fitzpatrick P, Catalysts, 2013,3 189-218.

27. Friedmann D, Mendive C, Bahnemann D,Applied Catalysis B: Environmental, 2010, 99, 398-406.

28. Ahmed H, Abbas L, Zahra A, Falah H, Asian Journal of Chemistry, 2014, 26, 167-172.

29. Matos J, Laine J, Herrmann M, Uzcategui D, Brito L, Applied Catalysis B: Environmental, $2007,70,461-469$.

30. Ashri W, Daud W, Houshamnd A, Journal of Natural Gas Chemistry, 2010, 19, 267279. 
31. Rusheng Y, Rogngbo G, JingtangZ, Scripta Materialia, 2005, 62 ,1329-1334.

32. Ahmed K, Falah $\mathrm{H}$, Ahmed $\mathrm{H}$, Bahnemann D, International Journal of Photoenergy, 2014, 2014, 2-9.

33. Sobana N; Swaminathan M, Solar Energy Materials and Solar Cells, 2007, 91, 727-734.
34. GokonaN; Hasegawa N, KanekoH, Aoki H, TamauraY, KitamuaraM, Solar Energy Materials and Solar Cells, 2003, 80 , 335-341.

35. Suna H, Yong K, Suna X, Donga Y,Materials Chemistry and Physics, 2009, 115(1), 303-308.

36. Movahedi M, Mahjoub R, Darzi J, Journal of the Iranian Chemical Society, 2009, 6(3), 570-577. 